Article

\title{
APOE Polymorphisms Contribute to Reduced Atorvastatin Response in Chilean Amerindian Subjects
}

\author{
Jenny Lagos, Tomás Zambrano, Alexy Rosales and Luis A. Salazar * \\ Center of Molecular Biology and Pharmacogenetics, Department of Basic Sciences, \\ Scientific and Technological Bioresource Nucleus, Universidad de La Frontera (BIOREN-UFRO), \\ Av. Francisco Salazar 01145, 4811230 Temuco, Chile; E-Mails: tm.jenny.lagos@gmail.com (J.L.); \\ t.andreszambrano@gmail.com (T.Z.); tm.arosales@gmail.com (A.R.) \\ * Author to whom correspondence should be addressed; E-Mail: luis.salazar@ufrontera.cl; \\ Tel.: +56-45-2592-895 or +56-45-2592-834; Fax: +56-45-2592-832.
}

Academic Editor: Emil Alexov

Received: 19 March 2015 / Accepted: 3 April 2015 / Published: 9 April 2015

\begin{abstract}
Genetic factors can determine the high variability observed in response to lipid-lowering therapy with statins. Nonetheless, the frequency of single nucleotide polymorphisms (SNPs) and their impact can vary due to ethnicity. Because the Chilean population carries a strong Amerindian background, the objective of this study was to evaluate the influence of apolipoprotein $\mathrm{E}(A P O E)$ variants (rs429358, rs7412) and the $1959 \mathrm{C}>\mathrm{T}$ SNP (rs5925) in the low-density lipoprotein receptor $(L D L R)$ in response to atorvastatin treatment in hypercholesterolemic individuals. A hundred and thirty nine subjects undergoing statin therapy were included. Identification of Amerindian mtDNA haplogroups was determined by polymerase chain reaction (PCR) and PCR followed by restriction fragment length polymorphism (RFLP), respectively. SNPs were determined by PCR-RFLP. Out of the 139 individuals studied, 84.4\% had an Amerindian background, according to mtDNA analysis. In relation to $A P O E$ variants, carriers of the E3/4 genotype presented lower cholesterol reduction compared to genotype E3/3 (LDL-C: $-18 \%$ vs. $-29 \%$, $p<0.001)$. On the other hand, the $L D L R$ rs5925 SNP was not related to atorvastatin response $(p=0.5760)$. Our results suggest that $A P O E$ SNPs are potential predictors to atorvastatin therapy in Amerindian Chilean subjects.
\end{abstract}

Keywords: atorvastatin; $A P O E$; $L D L R$; polymorphisms; pharmacogenetics; Amerindian 


\section{Introduction}

Elevated plasma levels of low-density lipoprotein cholesterol (LDL-C) are strongly associated as a key risk factor for cardiovascular disease. Clinical management of hypercholesterolemia using statins not only improves the lipid profile, but also has multiple atheroprotective effects, reducing mortality and the incidence of cardiovascular events $[1,2]$.

The effectiveness of statin therapy has been underlined by several studies. However, when an identical dose is used, a spectrum of different responses among treated individuals emerges. This interindividual variability in therapeutic response may be determined by several factors, such as biological and physiological conditions of the patient, treatment adherence, age, gender, ethnicity and genetic factors specific to each individual [3-5]. In this sense, pharmacogenetic studies have established that lipid-lowering response to statins can be affected by the presence of genetic variations in genes involved in central cholesterol-related processes like intestinal absorption, metabolism and in genes regulating the pharmacokinetics and pharmacodynamics of statins [6-10]. However, results obtained are not always reproducible, which could be partially influenced by the ethnical characteristics of the population studied [11]. Moreover, most pharmacogenetic investigations have been performed in Caucasian, Asian and African populations [12,13]. In contrast, Chilean subjects have an ethnic background differing from other world populations, reporting a high percentage of Amerindian population $[14,15]$. Characterization of this ethnical group can be achieved by means of mitochondrial DNA markers (mtDNA), making possible the identification of four haplogroups called A, B, C and D, through recognition of genetic variants [16,17].

As atorvastatin is the leading statin used in Chilean healthcare services, searching for pharmacogenetic markers of atorvastatin response to the characteristic Chilean population is of great interest. So, this work evaluated the influence of apolipoprotein $\mathrm{E}(A P O E)$ genotypes on the response to atorvastatin. In addition, as the low-density lipoprotein receptor $(L D L R)$ is another locus robustly associated to variability in LDL-C and statin response, the polymorphism rs5925, previously associated with low TC, LDL-C, HDL-C and TG in different groups of individuals [18,19], was also assessed in this study.

\section{Results}

Clinical and demographic characteristics of the study group are summarized in Table 1 . The reduction of plasma values of TC $(274 \pm 18.3 v s .224 \pm 26.0 \mathrm{mg} / \mathrm{dL} ;-18.2 \%)$, LDL-C (185 \pm 17.5 vs. $137 \pm 26.1 \mathrm{mg} / \mathrm{dL}$; $-25.9 \%)$ and TG $(213 \pm 50.5 v s .166 \pm 48.4 \mathrm{mg} / \mathrm{dL} ;-22.0 \%)$ were significant after completion of the treatment $(p<0.001)$. In addition, we observed an increase in HDL-C levels after atorvastatin therapy $(46.4 \pm 8.8$ vs. $54.1 \pm 6.7 \mathrm{mg} / \mathrm{dL} ;+14.8 \%)$. According to the ethnic characterization achieved by mitochondrial DNA analysis, we observed that 116 individuals $(84.4 \%)$ of the studied population was Amerindian (Table 1). Those individuals who did not have any of the A, B, C and D haplogroups were classified as non-Amerindian (15.6\%). Due to the low frequency of non-Amerindian $(n=16)$, it was not possible to perform a comparative analysis of statin response between Amerindian and non-Amerindian subjects.

Genotype distribution and relative allele frequencies for the studied polymorphisms are shown in Table 2. There were no differences in cholesterol levels when the $L D L R$ rs5925 variant was present 
(Table 3). However, carriers of E3/4 genotype of $A P O E$ had a lower TC, LDL-C and TG reduction when compared to the E3/3 genotype (Table 4). Genotypes E2/3 and E2/4 were not included in the comparative analysis due to their low frequency $(2.5 \%$ and $2 \%$, respectively).

Table 1. Clinical and demographic characteristics of the study group.

\begin{tabular}{cc}
\hline Parameter & $\boldsymbol{n}=\mathbf{1 3 9}$ \\
\hline Age (years) & $56.4 \pm 10.7$ \\
Men/Women $(n)$ & $87 / 52$ \\
BMI $\left(\mathrm{kg} / \mathrm{m}^{2}\right)$ & $25.6 \pm 2.7$ \\
Systolic blood pressure (mmHg) & $106.8 \pm 12.3$ \\
Diastolic blood pressure (mmHg) & $72.7 \pm 9.2$ \\
TC (mg/dL) & $274 \pm 18.3$ \\
TG (mg/dL) & $213 \pm 50.5$ \\
LDL-C (mg/dL) & $185 \pm 17.5$ \\
HDL-C (mg/dL) & $46 \pm 8.8$ \\
Haplogroup A & \\
Haplogroup B & 1.4 \\
Haplogroup C & 29.0 \\
Haplogroup D & 32.0 \\
Non-Amerindians & 22.0 \\
\hline
\end{tabular}

TC: total cholesterol; LDL-C: low-density lipoprotein cholesterol; HDL-C: high-density lipoprotein cholesterol; TG: triglycerides.

Table 2. Genotype distribution and relative allele frequencies for the polymorphisms studied in Amerindian hypercholesterolemic subjects $(n=116)$.

\begin{tabular}{cccccccc}
\hline & \multicolumn{4}{c}{ Genotypes } & \multicolumn{3}{c}{ Allele Frequency } \\
\hline $\boldsymbol{L D L R}$ & $\mathrm{CC}$ & $\mathrm{CT}$ & $\mathrm{TT}$ & $\mathrm{C}$ & $\mathrm{T}$ \\
$(r s 5925)$ & $22.4 \%$ & $66.4 \%$ & $11.2 \%$ & 0.556 & 0.444 \\
\hline $\boldsymbol{A P O E}$ & $2 / 3$ & $3 / 3$ & $3 / 4$ & $2 / 4$ & $\varepsilon 2$ & $\varepsilon 3$ & $\varepsilon 4$ \\
$(\mathrm{rs} 429358, \mathrm{rs} 7412)$ & $2.5 \%$ & $61.5 \%$ & $34 \%$ & $2 \%$ & 0.021 & 0.802 & 0.177 \\
\hline
\end{tabular}

Genotypes E2/2 and E4/4 were not found.

Table 3. Lipid profile and response to atorvastatin treatment $(10 \mathrm{mg} /$ day/4weeks $)$ according to the low-density lipoprotein receptor (LDLR) rs5925 polymorphism in hypercholesterolemic Amerindian subjects.

\begin{tabular}{cccccc}
\hline \multirow{2}{*}{ Lipids (mg/dL) } & \multirow{2}{*}{ Condition } & \multicolumn{3}{c}{ Genotypes } & \multirow{2}{*}{$\boldsymbol{p}$-Value } \\
\cline { 3 - 6 } & & $\mathbf{C C}(\boldsymbol{n}=\mathbf{2 5})$ & $\mathbf{C T}(\boldsymbol{n}=\mathbf{7 8})$ & TT $(\boldsymbol{n}=\mathbf{1 3})$ & \\
\hline \multirow{2}{*}{ TC } & basal & $271 \pm 14.4$ & $273 \pm 18.2$ & $283 \pm 22.1$ & 0.1080 \\
& treatment & $211 \pm 26.2$ & $226 \pm 27.3$ & $224 \pm 26.5$ & 0.2423 \\
& \% change & $-22.0 \pm 10.7$ & $-17 \pm 10.6$ & $-20.0 \pm 10.8$ & 0.3054 \\
\hline \multirow{2}{*}{ LDL-C } & basal & $190 \pm 16.1$ & $183 \pm 17.8$ & $192 \pm 20.0$ & 0.1989 \\
& treatment & $127 \pm 28.6$ & $139 \pm 27.5$ & $137 \pm 27.0$ & 0.4655 \\
& \% change & $-32.0 \pm 18.0$ & $-24 \pm 15.9$ & $-28.0 \pm 15.1$ & 0.2258 \\
\hline
\end{tabular}


Table 3. Cont.

\begin{tabular}{|c|c|c|c|c|c|}
\hline \multirow{2}{*}{ Lipids (mg/dL) } & \multirow{2}{*}{ Condition } & \multicolumn{3}{|c|}{ Genotypes } & \multirow{2}{*}{$p$-Value } \\
\hline & & $\mathrm{CC}(n=25)$ & CT $(n=78)$ & TT $(n=13)$ & \\
\hline \multirow[t]{3}{*}{ HDL-C } & basal & $48 \pm 6.0$ & $47 \pm 9.4$ & $46 \pm 7.8$ & 0.2643 \\
\hline & treatment & $55 \pm 6.0$ & $54 \pm 7.0$ & $53 \pm 6.3$ & 0.7850 \\
\hline & $\%$ change & $15.0 \pm 16.2$ & $18.0 \pm 14.7$ & $18.0 \pm 17.1$ & 0.9576 \\
\hline \multirow[t]{3}{*}{ TG } & basal & $197 \pm 53$ & $217 \pm 48.7$ & $224 \pm 51.0$ & 0.1047 \\
\hline & treatment & $146 \pm 48.6$ & $167 \pm 49.5$ & $172 \pm 48.9$ & 0.2499 \\
\hline & $\%$ change & $-25.0 \pm 24.6$ & $-23.0 \pm 17.9$ & $-22.0 \pm 22.9$ & 0.2305 \\
\hline
\end{tabular}

Values are expressed as mean \pm standard deviation; TC: total cholesterol; LDL-C: low-density lipoprotein cholesterol; HDL-C: high-density lipoprotein cholesterol; TG: triglycerides; $p$-values from ANOVA.

Table 4. Lipid profile and response to atorvastatin treatment (10 mg/day/4 weeks) according to apolipoprotein E $(A P O E)$ Genotypes in hypercholesterolemic Amerindian subjects.

\begin{tabular}{|c|c|c|c|c|}
\hline \multirow{2}{*}{ Lipids (mg/dL) } & \multirow{2}{*}{ Condition } & \multicolumn{2}{|c|}{ Genotypes } & \multirow{2}{*}{$p$-Value } \\
\hline & & $\mathrm{E} 3 / 3(n=72)$ & $\mathrm{E} 3 / 4(n=40)$ & \\
\hline \multirow[t]{3}{*}{$\mathrm{TC}$} & basal & $276 \pm 19.2$ & $275 \pm 18.7$ & 0.2630 \\
\hline & treatment & $218 \pm 23.3$ & $240 \pm 26.8$ & 0.0004 \\
\hline & $\%$ change & $-21.0 \pm 8.9$ & $-12.0 \pm 10.9$ & 0.0008 \\
\hline \multirow[t]{3}{*}{ LDL-C } & basal & $188 \pm 18.1$ & $183 \pm 18.4$ & 0.4561 \\
\hline & treatment & $132 \pm 25.3$ & $148 \pm 25.8$ & 0.0030 \\
\hline & $\%$ change & $-29.0 \pm 14.4$ & $-18.0 \pm 15.9$ & 0.0046 \\
\hline \multirow[t]{3}{*}{ HDL-C } & basal & $48 \pm 7.8$ & $51 \pm 11.1$ & 0.1626 \\
\hline & treatment & $54 \pm 6.8$ & $56 \pm 7.5$ & 0.1352 \\
\hline & $\%$ change & $20.0 \pm 14.8$ & $12.0 \pm 15.2$ & 0.0020 \\
\hline \multirow[t]{3}{*}{ TG } & basal & $215 \pm 50.2$ & $209 \pm 53.9$ & 0.5598 \\
\hline & treatment & $160 \pm 51.4$ & $181 \pm 45.8$ & 0.0263 \\
\hline & $\%$ change & $-25.0 \pm 20.0$ & $-12.0 \pm 18.1$ & 0.0127 \\
\hline
\end{tabular}

Values are expressed as mean \pm standard deviation; TC: total cholesterol; LDL-C: low-density lipoprotein cholesterol; HDL-C: high-density lipoprotein cholesterol; TG: triglycerides; $p$-values from paired $t$-test. Genotypes $2 / 3$ and $2 / 4$ were not subjected to statistical analysis due to their low frequency ( $2.5 \%$ and $2.0 \%$, respectively).

\section{Discussion}

Atorvastatin is effective in controlling high cholesterol and reducing cardiovascular risk. The overall LDL-C reduction can reach up to $37 \%$ in subjects using doses of $10 \mathrm{mg} /$ day for 4 weeks, regardless of cholesterol levels before starting the therapy. However, the response is variable between individuals, possibly due to factors such as gender, ethnicity or genetic composition [11]. As LDLR and APOE proteins hold important roles in lipid metabolism and the mechanism of action of statins, we analyzed the influence of the $L D L R$ rs5925 SNP and $A P O E$ genotypes on atorvastatin response in Chilean population with Amerindian background.

The main goal of statin therapy is the competitive and selective inhibition of the 3-hydroxy-3methylglutaryl-Coenzyme A reductase (HMG-CoA reductase) enzyme. This step determines the blocking of intracellular lipid synthesis and promotes the activation of a transcription factor known as 
Sterol Regulatory Element-Binding Proteins (SREBPs), inducing the expression of LDLR [20]. Consequently, $L D L R$ activity increase the number of receptors bound to the cell membrane that interacts with LDL, enhancing the clearance of this lipid fraction [20]. A major factor in this interaction is the presence of $A P O E$, which depending on its isoform, influences the binding affinity between the ligand and its receptor. APOE is a structural protein of lipoproteins, mediating the binding with the LDLR [21]. Several studies have replicated the association between the $\mathrm{C}$ allele of the rs5925 SNP and higher levels of cholesterol [22,23]. This same finding was reported recently by Long et al. [19], demonstrating that the CC genotype associates to a higher concentration of total and LDL-C when compared to CT and TT genotypes. In Brazil, it was demonstrated that among patients treated with fluvastatin, $\mathrm{C}$ allele carriers had higher lipid levels and lower cholesterol reduction [6]. However, our investigation did not show this association in Chilean Amerindian subjects. The different ethnic background in Chileans may be an interesting precedent that could condition the lack of association to treatment response and to hypercholesterolemia. Importantly, this finding is the first study of $L D L R$ SNP in Chileans associated to the pharmacogenetics of statins. As this variant did not show a relation with response, more studies exploring genetic variations in this receptor are needed to extend the current knowledge on its function and relationship to the therapeutic efficacy of atorvastatin.

In relation to the pharmacogenetics of statin therapy, one of the variants demonstrating more reproducibility with treatment response is the genotype E3/4 of APOE. This apolipoprotein is polymorphic, presenting three different isoforms (E2, E3 and E4) that are determined by six possible genotypes (E2/2, E2/3, E2/4, E3/3, E3/4, E4/4) from 3 different alleles (e2, e3 and e4). The three alleles are the result of nucleotide substitutions in codons 112 and 158 of exon 4 of the APOE gene [21]. While the most common isoform of apolipoprotein E is E3, current evidence shows that the E2 isoform would be associated with higher levels of LDL-C reduction compared to E3 and E4. Also, the E4 isoform has been associated with lower response to treatment [24,25]. Similarly, we also observed a lower lipid-lowering effect for the E3/4 genotype in response to atorvastatin, correlating this finding to a previous report documented by Baptista et al. [26]. The different $A P O E$ genotypes can determine various degrees of receptor affinity [21,24]. This finding is interesting in relation to the effectiveness of statins, since this drug promotes increased synthesis of receptors, and in the case of APOE E4, effectiveness would be limited by failure of union between ligand and receptor, independent of the number of receptors.

In addition to the improved lipid profile following atorvastatin therapy, decreasing plasma $\mathrm{TC}$, LDL-C and TG, we also observed a significant influence of APOE E3/4 genotype on TC and TG reduction. Several epidemiological studies have established a positive relationship between TG levels and CHD. Furthermore, two meta-analyses indicate that elevated TG are an independent risk factor for the development of coronary heart disease (CHD) [27,28], establishing an atherogenic role for triglyceride-rich lipoproteins and thus, conferring increasing interest to the clinical significance of $A P O E$ variants and the enhanced lipid reduction identified in our work.

Identification of mitochondrial DNA haplogroups determined that $84.4 \%$ of the subjects had an Amerindian background. This finding is consistent with a prior result, where an $85 \%$ of Amerindian individuals from Southern Chile was ascertain to have this ethnicity [29]. Currently, there are associations between polymorphisms in the mitochondrial genome and increased levels of LDL-C [26,30]. 
Nevertheless, in a previous report, we did not find an association of Amerindian mtDNA haplogroups with atorvastatin response [29].

A concern that could be limiting the results obtained is the reduced number of individuals included, which could be providing some bias. Therefore, additional studies assessing a greater cohort are key in order to corroborate and reproduce consistently the influence of $A P O E$ genotypes on plasma lipid levels. However, our findings highlight the identification of the E3/4 genotype as a potential and useful biomarker of atorvastatin response. This genotype is clinically informative; allowing the use of different treatment strategies, such as the use of higher doses of atorvastatin, complementation with an inhibitor of intestinal cholesterol absorption or simply receives different pharmacologic therapy to achieve the expected therapeutic goals in hypercholesterolemic patients.

In summary, our results partially explain the variability of therapeutic response to atorvastatin therapy in a Chilean cohort, demonstrating that the presence of genotype E3/4 of $A P O E$ determines a lower response to treatment with atorvastatin in Amerindian subjects. Taking into account that an adequate control of dyslipidemia contributes to improving mortality, morbidity and associated cardiovascular disease, it becomes evident the need of pharmacogenetic studies to elucidate other determinants of response to statin therapy in Chilean population.

\section{Experimental Section}

\subsection{Subjects}

As statins are the main lipid-lowering medication currently prescribed, being also safe and well tolerated, hypercholesterolemic patients $(n=139)$, diagnosed according to the NCEP criteria [31] were selected from the Federico Thieme Health Center (Región de La Araucanía, Chile) and treated with $10 \mathrm{mg} /$ day of atorvastatin during 4 weeks. None of the subjects had diabetes, hepatic, kidney, endocrinological or malignant disease, nor was receiving concomitant lipid-lowering therapy. Patients using medication that could affect the lipid profile, such as beta-blockers and diuretics, were excluded. All participants voluntarily signed an informed consent and the local Scientific Ethics Committee approved the study protocol.

\subsection{Biochemical Determinations}

Blood samples were obtained by venipuncture following a 12-h overnight fast. Biochemical measurements were determined by standard enzymatic-colorimetric methods (Human, Germany) and low-density lipoprotein cholesterol was calculated using Friedewald's formula, when triglycerides did not exceed $400 \mathrm{mg} / \mathrm{dL}$ ( $4.8 \mathrm{mmol} / \mathrm{L})$. The accuracy of biochemical determinations was controlled using normal and pathological commercial serums (Human, Germany).

\subsection{Molecular Analysis}

Genomic DNA was extracted from blood leukocytes by a salting out procedure optimized by Salazar et al. [32]. Genotyping was performed by PCR-RFLP. 


\section{4. mtDNA Haplogroups Genotyping}

The procedure was completed according to Moraga et al. [14]. Briefly, to determine the presence or absence of the three characteristic polymorphic restriction sites of haplogroups A, C and D of Amerindian population, we used 3 specific endonucleases (HaeIII, HincII and AluI). Finally, restriction fragments were evaluated in a $3 \%$ agarose gel electrophoresis followed by ethidium bromide staining. In order to define the haplogroup $\mathrm{B}$, a deletion of one out of two $9 \mathrm{bp}$ repeats located in the intergenic region $\mathrm{V}$ was visualized in a $10 \%$ polyacrylamide gel electrophoresis directly from the PCR products obtained.

\subsection{LDLR rs5925 Genotyping}

Genotyping was carried out through PCR amplification using specific primers (Forward: 5'-GTCATCTTCCTTGCCTGTTTAG-3'; Reverse: 5'-TTTCCACAAGGAGTTTTCAAGTT-3'), allowing amplification of a 228 bp within the sequence of the 13th exon. PCR amplification reactions were performed in a final volume of $25 \mu \mathrm{L}$ containing $50 \mathrm{ng}$ of genomic DNA, $200 \mathrm{nM}$ of each primer, $0.2 \mathrm{mM}$ of dNTPs (dATP, dTTP, dGTP, dCTP), 1 unit of Taq DNA polymerase, $2 \mathrm{mM}$ of $\mathrm{MgCl}_{2}$, PCR buffer ( $\mathrm{KCl} 50 \mathrm{mM}, 2 \mathrm{mM} \mathrm{MgCl}$, Tris- $\mathrm{HCl}, \mathrm{pH}$ 9.0) and sterile deionized water. The method was carried out in a Mycycler TM thermocycler (BioRad Laboratories Inc., Hercules, CA, USA) under the following temperatures scheme: initial denaturation at $98^{\circ} \mathrm{C}$ for $3 \mathrm{~min}$ followed by 35 cycles consisting on $95{ }^{\circ} \mathrm{C}$ for $1 \mathrm{~min}$ (denaturation), $66^{\circ} \mathrm{C}$ for $1 \mathrm{~min}$ (annealing) and $72{ }^{\circ} \mathrm{C}$ for $1 \mathrm{~min}$ (extension) with a final extension at $72{ }^{\circ} \mathrm{C}$ for $10 \mathrm{~min}$. Amplification products were evaluated in a $2 \%$ agarose gel electrophoresis stained with ethidium bromide and visualized in an UV transilluminator. PCR products were submitted to enzymatic digestion with Eco47I (Fermentas, Lituania) in the following reaction conditions for a final volume of $15 \mu \mathrm{L}$ : 1 unit of enzyme $(0.1 \mu \mathrm{L}), 1.5 \mu \mathrm{L}$ of enzyme buffer, $7 \mu \mathrm{L}$ of PCR product and sterile deionized water. Reactions were incubated at $37^{\circ} \mathrm{C}$ for $12 \mathrm{~h}$ Digestion products were revealed by $2 \%$ agarose gel electrophoresis, subsequently stained with ethidium bromide and visualized using an UV transilluminator.

\subsection{APOE Isoforms Genotyping}

PCR amplification assays using specific primers were performed (Forward: 5'-CTGACCCC GGTGGCGGA-3', Reverse: 5'-GGGGATGGGGCTGAGGC-3'), amplificating a 291 bp sequence within exon 4 of the gene. PCR amplification reactions were performed in a final volume of $25 \mu \mathrm{L}$ containing $50 \mathrm{ng}$ of genomic DNA, $200 \mathrm{nM}$ of each primer, $0.2 \mathrm{mM}$ of dNTPs (dATP, dTTP, dGTP, dCTP), 1 unit of Taq DNA polymerase, $1.5 \mathrm{mM}$ of $\mathrm{MgCl}_{2}$, PCR buffer ( $\mathrm{KCl} 50 \mathrm{mM}, 2 \mathrm{mM} \mathrm{MgCl}$, Tris-HCl, $\mathrm{pH} 9.0$ ), $0.75 \mu \mathrm{L}$ of DMSO and sterile deionized water. Amplification was carried out in a Mycycler TM thermocycler (BioRad Laboratories Inc.) under the following temperatures scheme: initial denaturation at $95{ }^{\circ} \mathrm{C}$ for $5 \mathrm{~min}, 30$ cycles: $95{ }^{\circ} \mathrm{C}$ for $1 \mathrm{~min}$ (denaturation), $62{ }^{\circ} \mathrm{C}$ for $1 \mathrm{~min}$ (annealing), $72{ }^{\circ} \mathrm{C}$ for $1 \mathrm{~min}$ (extension) and a final extension at $72{ }^{\circ} \mathrm{C}$ for $5 \mathrm{~min}$ Amplification products were evaluated in a $2 \%$ agarose gel electrophoresis stained with ethidium bromide and visualized in a UV transilluminator. PCR products were submitted to enzymatic digestion with $\mathrm{HhaI}$ (Fermentas, Lituania) in the following reaction conditions for a final volume of 15:1 unit of enzyme $(0.1 \mu \mathrm{L}), 1.5 \mu \mathrm{L}$ of enzyme buffer, $7 \mu \mathrm{L}$ of PCR product and sterile deionized water. Reactions were 
incubated at $37{ }^{\circ} \mathrm{C}$ for $12 \mathrm{~h}$. Following this, digestion products were revealed by $10 \%$ polyacrylamide gel electrophoresis, and were subsequently stained with ethidium bromide and visualized using an UV transilluminator.

\subsection{Data Analysis}

Results were analyzed using the Sigma Stat statistical software v. 2.0 (Jandel Sci, San Rafael, CA, USA). All variables were analyzed descriptively. Comparison of continuous variables was performed using Student's $t$ test or ANOVA one-way test. Comparison between proportions was evaluated by Chi-square or Fisher's exact test. Genotype and allele frequencies were obtained by direct gene counting. The statistical significance considered was $\alpha=0.05$.

\section{Acknowledgments}

This study was supported by Grants from FONDECYT-Chile (Grant Number 1130675). Jenny Lagos and Tomás Zambrano were recipients of a fellowship from CONICYT-Chile.

\section{Author Contributions}

Jenny Lagos performed the genetic and data analysis and wrote the paper; Alexy Rosales recruited the patients and the clinical data; Tomás Zambrano revised and wrote the paper; Luis A. Salazar designed and supervised the study and revised the paper.

\section{Conflicts of Interest}

The authors declare no conflict of interest.

\section{References}

1. Poss, J.; Custodis, F.; Werner, C.; Weingartner, O.; Bohm, M.; Laufs, U. Cardiovascular disease and dyslipidemia: Beyond LDL. Curr. Pharm. Des. 2011, 17, 861-870.

2. Wang, C.Y.; Liu, P.Y.; Liao, J.K. Pleiotropic effects of statin therapy: Molecular mechanisms and clinical results. Trends Mol. Med. 2008, 14, 37-44.

3. Kajinami, K.; Takekoshi, N.; Brousseau, M.E.; Schaefer, E.J. Pharmacogenetics of HMG-CoA reductase inhibitors: Exploring the potential for genotype-based individualization of coronary heart disease management. Atherosclerosis 2004, 177, 219-234.

4. Schmitz, G.; Langmann, T. Pharmacogenomics of cholesterol-lowering therapy. Vascul. Pharmacol. 2006, 44, 75-89.

5. Kajinami, K.; Akao, H.; Polisecki, E.; Schaefer, E.J. Pharmacogenomics of statin responsiveness. Am. J. Cardiol. 2005, 96, 65K-70K.

6. Salazar, L.A.; Hirata, M.H.; Quintao, E.C.; Hirata, R.D. Lipid-lowering response of the HMG-CoA reductase inhibitor fluvastatin is influenced by polymorphisms in the low-density lipoprotein receptor gene in Brazilian patients with primary hypercholesterolemia. J. Clin. Lab. Anal. 2000, 14, $125-131$. 
7. Lahoz, C.; Pena, R.; Mostaza, J.M.; Laguna, F.; Garcia-Iglesias, M.F.; Taboada, M.; Pintó, X. Baseline levels of low-density lipoprotein cholesterol and lipoprotein(a) and the AvaII polymorphism of the low-density lipoprotein receptor gene influence the response of low-density lipoprotein cholesterol to pravastatin treatment. Metabolism 2005, 54, 741-747.

8. Kajinami, K.; Brousseau, M.E.; Ordovas, J.M.; Schaefer, E.J. CYP3A4 genotypes and plasma lipoprotein levels before and after treatment with atorvastatin in primary hypercholesterolemia. Am. J. Cardiol. 2004, 93, 104-107.

9. Willrich, M.A.; Hirata, M.H.; Genvigir, F.D.; Arazi, S.S.; Rebecchi, I.M.; Rodrigues, A.C.; Bernik, M.M.; Dorea, E.L.; Bertolami, M.C.; Faludi, A.A.; et al. CYP3A53A allele is associated with reduced lowering-lipid response to atorvastatin in individuals with hypercholesterolemia. Clin. Chim. Acta 2008, 398, 15-20.

10. Fiegenbaum, M.; Silveira, F.R.; van der Sand, C.R.; van der Sand, L.C.; Ferreira, M.E.; Pires, R.C.; Hutz, M.H. Determinants of variable response to simvastatin treatment: The role of common variants of SCAP, SREBF-1A and SREBF-2 genes. Pharmacogenomics J. 2005, 5, 359-364.

11. Ferdinand, K.C. Ethnic, gender, and age-related differences in the treatment of dyslipidemia. Am. J. Manag. Care 2006, 12, S400-S404.

12. Simon, J.A.; Lin, F.; Hulley, S.B.; Blanche, P.J.; Waters, D.; Shiboski, S.; Rotter, J.I.; Nickerson, D.A.; Yang, H.; Saad, M.; et al. Phenotypic predictors of response to simvastatin therapy among African-Americans and Caucasians: The Cholesterol and Pharmacogenetics (CAP) Study. Am. J. Cardiol. 2006, 97, 843-850.

13. Krauss, R.M.; Mangravite, L.M.; Smith, J.D.; Medina, M.W.; Wang, D.; Guo, X.; Rieder, M.J.; Simon, J.A.; Hulley, S.B.; Waters, D.; et al. Variation in the 3-hydroxyl-3-methylglutaryl coenzyme a reductase gene is associated with racial differences in low-density lipoprotein cholesterol response to simvastatin treatment. Circulation 2008, 117, 1537-1544.

14. Moraga, M.L.; Rocco, P.; Miquel, J.F.; Nervi, F.; Llop, E.; Chakraborty, R.; Rothhammer, F.; Carvallo, P. Mitochondrial DNA polymorphisms in Chilean aboriginal populations: Implications for the peopling of the southern cone of the continent. Am. J. Phys. Anthropol. 2000, 113, 19-29.

15. Rocco, P.; Morales, C.; Moraga, M.; Miquel, J.F.; Nervi, F.; Llop, E.; Carvallo, P.; Rothhammer, F. Genetic composition of the Chilean population. Analysis of mitochondrial DNA polymorphism. Rev. Med. Chile 2002, 130, 125-131.

16. Santos, S.E.; Ribeiro-Dos-Santos, A.K.; Meyer, D.; Zago, M.A. Multiple founder haplotypes of mitochondrial DNA in Amerindians revealed by RFLP and sequencing. Ann. Hum. Genet. 1996, 60, 305-319.

17. Bailliet, G.; Rothhammer, F.; Carnese, F.R.; Bravi, C.M.; Bianchi, N.O. Founder mitochondrial haplotypes in Amerindian populations. Am. J. Hum. Genet. 1994, 55, 27-33.

18. Liu, A.P.; Zhan, S.Y.; Li, L.M.; Hu, Y.H.; Cao, W.H.; Wu, T.; Li, J.; Guo, X.X. Association between AvaII exon 13 polymorphism at the LDL receptor gene different and serum lipid levels in normotensives and essential hypertensives in Shanghai. Zhonghua Liu Xing Bing Xue Za Zhi 2003, $24,542-546$. 
19. Long, X.J.; Yin, R.X.; Li, K.L.; Liu, W.Y.; Zhang, L.; Cao, X.L.; Miao, L.;Wu, D.F.; Htet Aung, L.H.; $\mathrm{Hu}$, X.J. Low density lipoprotein receptor gene Ava II polymorphism and serum lipid levels in the Guangxi Bai Ku Yao and Han populations. Lipids Health Dis. 2011, 10, doi:10.1186/1476-511X-10-34.

20. Istvan, E.S. Structural mechanism for statin inhibition of 3-hydroxy-3-methylglutaryl coenzyme A reductase. Am. Heart J. 2002, 144, S27-S32.

21. Hatters, D.M.; Peters-Libeu, C.A.; Weisgraber, K.H. Apolipoprotein E structure: Insights into function. Trends Biochem. Sci. 2006, 31, 445-454.

22. Ahn, Y.I.; Kamboh, M.I.; Aston, C.E.; Ferrell, R.E.; Hamman, R.F. Role of common genetic polymorphisms in the LDL receptor gene in affecting plasma cholesterol levels in the general population. Arterioscler. Thromb. 1994, 14, 663-670.

23. Liu, A.; Zhan, S.; Li, L. The relationship of low density lipoprotein receptor gene polymorphism and hyperlipidemia. Zhonghua Liu Xing Bing Xue Za Zhi 2001, 22, 30-33.

24. Mahley, R.W.; Rall, S.C., Jr. Apolipoprotein E: Far more than a lipid transport protein. Annu. Rev. Genomics Hum. Genet. 2000, 1, 507-537.

25. Hagberg, J.M.; Wilund, K.R.; Ferrell, R.E. APOE gene and gene-environment effects on plasma lipoprotein-lipid levels. Physiol. Genomics 2000, 4, 101-108.

26. Baptista, R.; Rebelo, M.; Decq-Mota, J.; Dias, P.; Monteiro, P.; Providencia, L.A.; Silva, J.M. Apolipoprotein E epsilon-4 polymorphism is associated with younger age at referral to a lipidology clinic and a poorer response to lipid-lowering therapy. Lipids Health Dis. 2011, 10, doi:10.1186/ 1476-511X-10-48.

27. Austin, M.A.; Hokanson, J.E.; Edwards, K.L. Hypertriglyceridemia as a cardiovascular risk factor. Am. J. Cardiol. 1998, 81, 7B-12B.

28. Assmann, G.; Schulte, H.; Funke, H.; von Eckardstein, A. The emergence of triglycerides as a significant independent risk factor in coronary artery disease. Eur. Heart J. 1998, 19, M8-M14.

29. Lagos, J.; Zambrano, T.; Rosales, A.; Salazar, L.A. Influence of SREBP-2 and SCAP gene polymorphisms on lipid-lowering response to atorvastatin in a cohort of Chilean subjects with Amerindian background. Mol. Diagn. Ther. 2014, 18, 435-443.

30. Kokaze, A.; Ishikawa, M.; Matsunaga, N.; Yoshida, M.; Sekine, Y.; Teruya, K.; Takeda, N.; Sumiya, Y.; Uchida, Y.; Takashima, Y. Association of the mitochondrial DNA 5178 A/C polymorphism with serum lipid levels in the Japanese population. Hum. Genet. 2001, 109, 521-525.

31. Grundy, S.M.; Cleeman, J.I.; Merz, C.N.; Brewer, H.B., Jr.; Clark, L.T.; Hunninghake, D.B.; Pasternak, R.C.; Smith, S.C., Jr.; Stone, N.J.; National Heart, Lung, and Blood Institute. Implications of recent clinical trials for the National Cholesterol Education Program Adult Treatment Panel III guidelines. Circulation 2004, 110, 227-239.

32. Salazar, L.A.; Hirata, M.H.; Cavalli, S.A.; Machado, M.O.; Hirata, R.D. Optimized procedure for DNA isolation from fresh and cryopreserved clotted human blood useful in clinical molecular testing. Clin. Chem. 1998, 44, 1748-1750.

(C) 2015 by the authors; licensee MDPI, Basel, Switzerland. This article is an open access article distributed under the terms and conditions of the Creative Commons Attribution license (http://creativecommons.org/licenses/by/4.0/). 